\title{
Can Bio-Based Thermoset Polymers Replace Petrochemical Based Counterparts?
}

\author{
Kayode Feyisetan Adekunle ${ }^{*}, 1,2$ \\ ${ }^{1}$ Department of Chemical Engineering, College of Engineering and Engineering Technology, Michael Okpara \\ University of Agriculture, Umudike, Abia State, Nigeria \\ ${ }^{2}$ School of Engineering, University of Boras, Sweden
}

\begin{abstract}
Specific answers are required for purpose of better communication with many researchers, manufacturers, and users of polymer worldwide. This paper posted so many questions about the research activities on bio-based/ renewable thermoset polymers as against petrochemical based thermoset polymers. Quite a few answers were given but the remaining unanswered questions will surely be required in order to better understand the results achieved in this research area.
\end{abstract}

Keywords: Renewable, cost-effective, synthesis, environmentally friendly.

\section{INTRODUCTION}

Thermoset polymers are being used in many industrial applications and most common areas are in composite manufacturing and coatings. Thermoset polymers may be from petrochemical origin or renewable sources. As technologies evolve, there have been many indications that there are better ways of synthesizing bio-based thermoset resins taking into consideration the environmental attributes, cost implications and their performances in high end technical applications.

Many researchers are working round the clock to make better resins from renewable origin and to find a best economic ways for their mass production in order for the renewable resins to compete with their counterparts from petrochemical sources. Interestingly the curing of bio-based resins is similar to that of the unsaturated polyester resins from petrochemical origin but in the long run do they ultimately perform the same functions in terms of overall mechanical properties? And if they do at the commencement of their usage, do they maintain the same properties over a long period of usage? Are they well tested, to the extent that researchers can convince manufacturers of composites to employ these renewable polymers in their productions? How many years are needed for the biobased resins to be tested and conclusion drawn that yes they ultimately perform exactly the same way as the thermoset resins from petrochemical?

\footnotetext{
*Address correspondence to this author at the Department of Chemical Engineering, College of Engineering and Engineering Technology, Michael Okpara University of Agriculture, Umudike, Abia State, Nigeria;

Tel: +234 803251 2177;

E-mails:k_adekunle@yahoo.co.uk, kayode.adekunle@hb.se
}

Some of the bio-based resins are in commercial quantities and are mostly used in coatings and matrix for composite manufacturing which have applications in marine, automobile, furniture, sport and construction. Aviation is the most capital intensive investment and more air crafts are being manufactured yearly costing trillions of dollars in investment, my question is that are the bio-based resins being used in the composites made for air crafts? If the bio-based resins are found to be more environmentally friendly, renewable, cost effective and having excellent mechanical properties why have they not been embraced by the aviation industry?

For a new product coming into the market the unique sale proposition should be cost effectiveness and equal or better performance. It is not enough to roll out research papers on new ways of manufacturing thermoset resins but their economic viability should be determined and most importantly the comprehensive environmental impact assessment be carried out. Government of many nations are talking about global warming, environmental impact of using products from finite sources such as fossil fuel but how much are they actually investing in the development of these new fantastic products from agricultural origin if they are really perceived as partly solution to global warming?

In view of the questions posted above, the stake holders in the resin and composite industries should urgently and as a matter of necessity address these issues if the interest is to keep our ecological system safe even for the unborn generation.

Unsaturated polyester resins are commonly used in fiber-reinforced composites as matrix resins [1]. Unsaturated polyesters are one of the oldest types of resins used in composites applications. The resin is 
composed of unsaturated polyester that is dissolved in styrene [1]. During the processing, the double bond in the polyester reacts with the styrene monomer in a free radical reaction that gives a rigid thermoset. Adekunle et al. [2] synthesized bio-based thermoset resins from soybean oil and the curing was done by the addition of a free radical initiator, $t$-butyl peroxybenzoate which gives a rigid thermoset polymer after short exposure to heat. A thermoset resin is useless in composite manufacturing on its own unless the resin can be permanently cured to a rigid polymer. The crosslinking or curing reaction is very complex, and reaction can take place between two styrene monomers (homopolymerisation), between styrene and a double bond in the polyester chain (intermolecular crosslinking or branching), and between two double bonds in the polyester chains (intramolecular crosslinking) [3]. The goal of synthesizing thermoset resin is to have as much double bonds as possible (crosslinkable functionalities) which will be involved in the curing or crosslinking in order to achieve a rigid thermoset [2]. Styrene and tbutyl peroxybenzoate are commonly used as free radical initiator but on the other hand they are injurious to human health because they are regarded as volatile organic compounds. Heating up a component containing styrene brings out an offensive smell that can be damaging.

If the crosslinkers used in both the curing of biobased and petrochemical based resins are not environmental friendly, then how can we justify the renewability and environmental friendliness of the products? Can an ecological crosslinker be used in order to have completely bio-based and renewable thermoset polymers? If such ecological crosslinkers are available, how effective are they? Have they been tested? Can they actually initiate curing and produce rigid thermoset in less than five (5) minutes as we have in conventional crosslinkers?

So many parameters are to be considered before a new product can substitute a tested and proven one. So what am I communicating?

Having been involved so much in synthesizing, curing and manufacturing of composites for several years, I have come to a conclusion that it is impossible to talk about renewable resins or bio-based composites without actually taking into consideration the parameters such as hours of synthesis, energy involved, volatile compounds used as monomers, several monomers involved, cost of the components and so on.

An economical way of producing the bio-based thermoset polymers should be looked into, a novel way of synthesizing without necessarily using excessive heat and long hours in polymerization reaction. Renewable monomers should be used instead of the volatile organic compounds presently in use in both the synthesis and curing of the bio-based resin. Further research should be done in the area of developing biobased cross linkers which will ultimately increase the renewable contents of the bio-based/ renewable resin. The neat plant seed oils usually go through epoxidation reaction and as it is today it is not sustainable. Biobased thermoset polymers are also suffering from lower strength and lack of batch-to-batch consistency.

On the other hand, plant seed oils can be over produced because they are from agricultural origin and this can actually reduce the price of the plant oils. Some of the monomers use in synthesis are expensive and this may contribute to the overall cost of the biobased resin. For the bio-based resin to compete favorably with conventional resin, they must be cheaper and affordable and ultimately perform similar function or even better than their conventional counterparts.

\section{CONCLUSION}

In the research world knowledge are supposed to be shared appropriately in order not to set a bad precedence. There are so many published books and research articles presenting conflicting information on the subject of renewable polymers and bio-based composites and if the trend continues it would not be too good for the polymer community.

\section{REFERENCES}

[1] Hietalahti K, Skrifvars M, Root A, Sundhlom F. Correlation of Viscoelastic Properties with Low-Resolution ${ }^{1} \mathrm{H}-\mathrm{NMR}$ Measurements of Crosslinking Unsaturated Polyesters. J Appl Polym Sci 1998; 68: 671-80. http://dx.doi.org/10.1002/(SICI)10974628(19980425)68:4<671::AID-APP19>3.0.CO;2-U

[2] Adekunle KF, Åkesson D, Skrifvars M. Synthesis of Recative Soybean Oils for Use as a Biobased Thermoset Resins in Structural Natural Fiber Composites. J Appl Polym Sci 2010; 115: 3137-45. http://dx.doi.org/10.1002/app.31411

[3] Yang YS, Lee LJ. Microstructure formation in the cure of unsaturated polyester resins. Polymer 1998; 29: 1793-800. http://dx.doi.org/10.1016/0032-3861(88)90393-X 